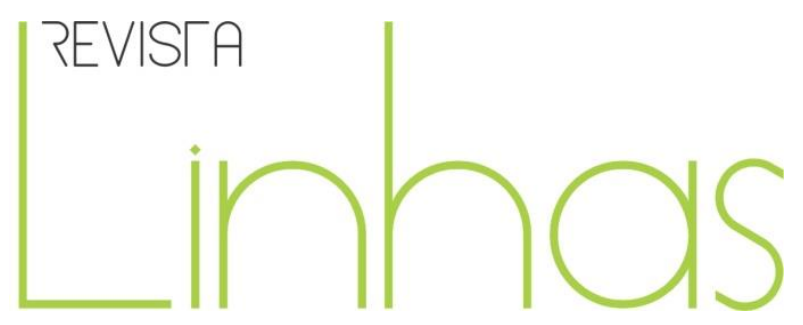

\title{
Duas senhoras e atrizes de respeito fazendo sem- vergonhice na TV!
}

\begin{abstract}
Resumo
O nosso texto é organizado a partir da fundamentação teórica da análise de discurso de orientação francesa (doravante, AD), sobretudo, a partir do conceito de Formação Imaginária de GADET E HAK (1993), além disso, a noção de Imaginário de MAFFESOLI (2001b) também contribui teoricamente para as leituras e análises realizadas por nós. Diante disso, nos propomos a analisar sete comentários que discorrem, principalmente, sobre a sexualidade e a homossexualidade feminina na velhice, os quais irrompem a partir da postagem no site do Youtube de uma cena do primeiro capítulo da novela Babilônia, exibida no horário nobre da Rede Globo de televisão. Por comentário, compreendemos o que FOUCAULT (1970) nos sugere para o seu modo de produzir sentido: há, segundo esse autor, dois papeis solidários no funcionamento dos comentários: primeiro, que ele permite construir novos discursos a partir do texto base, ou seja, ele funda a possibilidade aberta de falar, e, ainda, que também nele pode-se, enfim, articular o que se encontrava silenciado no texto primeiro. A partir dos estudos desenvolvidos, constatamos que esses comentários fundamentam-se em reproduções de crenças religiosas, de verdades científicas do século XIX, de concepções e certezas sobre as identidades de gênero e orientação sexual e, principalmente, sobre a sexualidade feminina na velhice.
\end{abstract}

Palavras-chave: Sexualidade; Homossexualidade; Imaginário; Análise do Discurso; Mídia.

\section{Alexandre Sebastião Ferrari Soares}

Universidade Estadual do Oeste

do Paraná - UNIOESTE - PR/Brasil asferraris@globo.com

Andréa Cristina Martelli

Universidade Estadual do Oeste do Paraná - UNIOESTE PR/Brasil

andreamartelli72@hotmail.com

\footnotetext{
Para citar este artigo:

SOARES, Alexandre Sebastião Ferrari; MARTELLI, Andréa Cristina. Duas senhoras e atrizes de respeito fazendo sem-vergonhice na TV! Revista Linhas. Florianópolis, v. 17, n. 34, p. 103-131, maio/ago. 2016.
}

\section{DOI: $10.5965 / 1984723817342016103$}

http://dx.doi.org/10.5965/1984723817342016103

\footnotetext{
${ }^{1} \mathrm{O}$ título do artigo foi retirado de um dos comentários postados no site do Youtube, e faz parte do corpus de análise desse artigo.
} 


\title{
Two respected ladies and actresses doing shameless on TV!
}

\begin{abstract}
Our paper is based on the theoretical foundation of the French discourse analysis (AD), especially from the concept of Imaginary Formation by the authors Gadet and HAK (1993). We also use the notion of Imaginary by MAFFESOLI (2001b) that contributes theoretically to the readings and analyzes made by us. With regard to that, we propose to analyze seven comments that discourse mainly about sexuality and female homosexuality in old age from Youtube posts (www.youtube.com): a scene from the first chapter of the soap opera Babilônia, aired on primetime Globo TV. For comments, we understand what Foucault (1970) suggests: there are two mutual roles on the scene: First it allows you to build new discourses from the basic text, i.e. it allows the opportunity to speak; and it also articulates what was silenced in the first text. From the conducted studies we verify that these comments are based on reproductions of religious beliefs, scientific truths of the nineteenth century, concepts and certainties about gender identity and sexual orientation, and mainly about female sexuality in old age.
\end{abstract}

Keywords: Sexuality; Homosexuality; Imaginary; Discourse Analysis; Media. 


\section{Sexualidade: o nosso lugar}

A sexualidade é um tema complexo e constituinte de todas as relações sociais. Para compreendê-la, precisamos lançar mão dos conhecimentos das diferentes ciências sociologia, psicologia, história, biologia, dentre outras - ao mesmo tempo, compreender os princípios religiosos, morais e éticos apreendidos nas diferentes instâncias sociais que influenciam as acepções, os discursos e as suas vivências. Nossa sexualidade envolve crenças, ideologias, rituais, imaginações, símbolos, convenções (LOURO, 2007, p. 11) e representações no uso do corpo e de seus prazeres (WEEKS, 2007, 43).

A sociedade ocidental, normalmente educada com base em paradigmas judaicocristãos, tem na noção de "pecado" a justificativa para anular ou denegar seus desejos e práticas afetivo-sexuais.

Derivam dessa relação o modo como as pessoas foram educadas, as repressões vivenciadas por elas ao longo de sua vida, os apelos da família e da sociedade, que contribuem para gerar pessoas medrosas, inseguras quanto aos seus próprios desejos e atitudes, sobretudo no que diz respeito ao domínio afetivo-sexual. Isso gera um círculo vicioso de pais que transmitem tais padrões morais, éticos e religiosos aos seus descendentes, e assim sucessivamente, formando-se pessoas com um pensamento cada vez mais homogêneo, caso não reconheçam e não rejeitem certos legados culturais. (ALMEIDA, LOURENÇO, 2008, p. 134, grifos nossos)

No imaginário social, prevalece o significado de sexualidade reduzido aos órgãos genitais, aos hormônios ou à reprodução, no entanto, em nossas concepções, a biologia é uma de suas dimensões. Construímos nossa sexualidade nas trocas com o mundo e com os outros; criamos seus sentidos e significados (GUIMARÃES, 1995, p. 31). Em outras palavras, seus significados e conteúdos alteram-se ao longo da história, nas diferentes sociedades e nos diferentes grupos sociais, numa mesma sociedade, bem como no decorrer da vida da mesma pessoa (LOYOLA, 1999, p. 36).

No início do Século XIX, o termo sexualidade foi criado relacionado a outros acontecimentos: "o desenvolvimento de campos de conhecimentos diversos; a instauração de um conjunto de regras e de normas", algumas novas, outras 
tradicionais, apoiadas "em instituições religiosas, judiciárias, pedagógicas e médicas; como também as mudanças no modo pelo qual os indivíduos são levados a dar sentido e valor à sua conduta, seus deveres, prazeres, sentimentos, sensações e sonhos" (FOUCAULT, 2003, p. 9).

Segundo Foucault (1995, p. 244), a sociedade ocidental criou dispositivos "discursos, instituições, organizações arquitetônicas, decisões regulamentares, leis, medidas administrativas, enunciados científicos, proposições filosóficas, morais, filantrópicas" - da sexualidade. Esses proliferam, inovam, inventam e penetram nos corpos de maneira mais detalhada e controlam as pessoas de maneira cada vez mais global (FOUCAULT, 2005a, p. 101).

No entanto, apesar das tentativas sociais de homogeneizar a sexualidade por meio de discursos normalizadores, da construção de "verdades" e do uso de dispositivos, os sujeitos constroem maneiras particulares de viver suas sexualidades.

Na sociedade ocidental, pratica-se a scientia sexualis, desenvolvida a partir do século XIX; nessa sociedade, "não se ensina a fazer amor, a obter o prazer, a dar prazer aos outros, a maximizar, a intensificar seu próprio prazer pelo prazer dos outros" (FOUCAULT, 2005a, p. 57-58). Há uma forma aceita socialmente de viver a sexualidade, a heterossexualidade e, tudo que foge a esse padrão, será banido, estigmatizado e julgado.

As vivências da sexualidade são contornadas por ambiguidades. Se, de um lado, os dispositivos controlam as sexualidades, por outro, possibilitam a criação de brechas, de desvios e de fugas desses controles.

Cada pessoa vive e experimenta formas inusitadas de sexualidade, oscilando entre o permitido e o proibido. Nessa perspectiva, precisamos nos libertar de estereótipos, "de conhecimentos sociais previamente concebidos, os quais conduzem o pensar e o agir sobre o mundo, a um único sentido, a uma única direção" (JESUS, 2007, p. 191), os quais nos conduzem a conceber e a viver a sexualidade dentro de uma possibilidade única, fixa e rígida.

Entretanto, vivemos nossa sexualidade no movimento entre racionalidades, crenças, mitos, preconceitos, tabus, dentre outros elementos que constituem nossa formação imaginária. A relação entre as intimações objetivas, os limites que as 
sociedades nos impõem e as subjetividades (MAFFESOLI, 2001b, p. 80) desenham o mosaico da vivência da nossa sexualidade. Por mais que sejamos tolhidos, somos sexuados. A sexualidade está ali, latente, latejando, pulsando. Cada pessoa reage de uma forma; umas conseguem se libertar das injunções familiares e religiosas, mas outras sucumbem a elas.

Às vezes, nos flagramos sendo obedientes às regras de comportamento impostas pela família e religião e, em outras vezes, transgredimos de modo astuto essas mesmas regras. Somos pessoas errantes, vivendo nossa pluralidade e a duplicidade de nossas existências (MAFFESOLI, 2001a, p. 16). É pela duplicidade, mais ou menos consciente, que as pessoas, aparentemente enquadradas aos padrões sociais, conseguem sobreviver às diferentes imposições desses (MAFFESOLI, 2001C, p. 97).

Vivemos nossas sexualidades numa aparência de que aceitamos os papéis impostos pela sociedade e resistimos em sair da mesmice cotidiana que sufoca nosso "querer-viver". Os modelos estão tão arraigados em nossas entranhas que nos permitimos viver somente o oficializado, o aceito e o considerado normal. Passamos nossas vidas encenando os papéis do que se considera ser boa moça e bom rapaz; seguimos os rituais religiosos apreendidos na infância, no seio familiar; sonhamos com o casamento perfeito e se, porventura, o mesmo não nos trouxer satisfação, resistimos em realizar uma ruptura.

Em outras vezes, esquivamo-nos das imposições geradas pela sociedade, abusando da liberdade, aniquilando nossas autocertezas e partilhando emoções e prazeres comuns. Com a ética, aprendemos a conviver com as diferenças e o estranhamento, realizando um trabalho de interrogação sobre nós mesmos, de nossos valores diante da vida e das pessoas.

Fomos social e culturalmente educados para seguir um modelo de homem e de mulher e, se por acaso não nos encaixamos nesse modelo, sentimo-nos excluídos pela sociedade. Há tentativa enfática da negação de outras formas de viver, experimentar ou expressar a sexualidade que fuja da linearidade, sexo-gênero-sexualidade; dito de outro modo, homem ou mulher, masculino ou feminino, heterossexual ou heterossexual. 


\section{Imaginário e formação imaginária: Maffesoli e Pêcheux, nossos interlocutores}

Nesse texto, dialogaremos com o imaginário e a formação imaginária. Tanto para Maffesoli (2001b) quanto para Gadet \& Hak (1993), o imaginário não está desvinculado do social. Ele se materializa no cotidiano dos sujeitos por meio dos discursos e das práticas sociais, proporcionando sentido a sua realidade. A sua interpretação do real, permeada pela língua, marca o lugar que esses sujeitos ocupam e a forma como expressam seus imaginários, ou seja, sujeito e sentido se fazem ao mesmo tempo.

Compreendemos o imaginário social como "um conjunto coordenado de representações, uma estrutura de sentidos, de significados que circulam entre seus membros [da sociedade], mediante diferentes formas de linguagem" (TEVES, 1992, p. 17). Nesse imaginário, "a polissemia das situações e a polissemia das palavras entram num balé sem fim, remetem incessantemente uma a outra e inserem-se, enfim, num vasto espectro cênico, o qual pode ser resumido na expressão imaginário social” (MAFFESOLI, 2005b, p. 58).

Guimarães (2004, p. 61), fundamentada em Maffesoli, argumenta que o cotidiano é resultado de dois polos: "de um lado, a organização política e econômica do social, de outro, um processo feito de acasos, de passividade, das paixões, dos encontros, das coerções e das pequenas mortes de todos os dias". O imaginário evidencia a carga simbólica presente nas sociedades complexas. A cultura ocidental é complexa, portanto, sua explicação não ocorre a partir de um só elemento, mas sim, sob sua pluralidade, cujos elementos são integrados pelo simbólico.

Nesse sentido, a noção de "imaginário" estará presente em nossas escritas; essa noção se faz compreender a partir de Maffesoli, inspirado em Gilbert Durand. Para esses autores, o imaginário "é a relação entre as intimações objetivas e a subjetividade. As intimações objetivas são os limites que as sociedades impõem a cada ser. Relação entre as coerções sociais e a subjetividade" (MAFFESOLI, 2001b, p. 80).

Os fenômenos sociais não se limitam aos fatos observáveis e racionais; os sonhos, o lúdico, a imagem, o simbólico, a imaginação, as fantasias, o onírico também pertencem a esses. Diferentemente do que o racionalismo ocidental defende, o imaginário não é a 
negação do real, mas a criação de novas relações, de um modo de conhecimento que saiba integrar aspectos considerados como secundários: o frívolo, a emoção, a aparência. Construindo uma hiper-racionalidade (MAFFESOLI, 2005a, p. 11), não há como denegar nada daquilo que nos cerca nesse mundo, no qual estamos e que é, "ao mesmo tempo, sentimento e razão" (MAFFESOLI, 2005a, p. 59).

A partir disso, a análise de discurso de orientação francesa nos permite, já que compactua com os princípios de imaginário de Michel Maffesoli, compreender de que forma, nesses comentários, irrompem sentidos sobre a sexualidade e a homossexualidade feminina.

Sobre a teoria que nos dá suporte para as análises, a AD, de orientação francesa, é importante destacar o que Gadet \& Hak (1993, p. 82) afirmam sobre o lugar que os interlocutores ocupam na estrutura de uma formação social ser evidenciado a partir das supostas Formações Imaginárias, (doravante, FI) colocadas em jogo no discurso. Além disso, encontra-se também em evidência a compreensão das condições de produção desse processo discursivo. O que significa dizer que o locutor, a partir do seu lugar, tem a habilidade de prever onde o seu interlocutor o espera. Consequentemente, a antecipação do que o outro vai pensar é constitutiva de qualquer discurso.

Fica bem claro, já de início, que os elementos A e B designam diferente da presença física de organismos humanos individuais. Se o que dissemos antes faz sentido, resulta, pois, dele que A e B designam lugares determinados na estrutura de uma formação social, lugares dos quais a sociologia pode descrever o feixe de traços objetivos característicos: assim, por exemplo, no interior da esfera de produção econômica, os lugares do "patrão" (diretor, chefe da empresa etc.), do funcionário de repartição, do operário, são marcados por propriedades diferenciais determináveis (GADET \& HAK, 1993, p. 82, grifos nossos)

A FI, entretanto, não diz respeito apenas à imagem que os interlocutores atribuem a si (e ao outro); ela diz respeito também à imagem que eles atribuem ao referente, ou seja, o ponto de vista dos interlocutores sobre o imaginário. Segundo Gadet \& Hak (1993), todo processo discursivo supõe a existência das seguintes FI: 
IA(A): Imagem do lugar de A para o sujeito colocado em A - Quem sou eu para lhe falar assim?

IA(B): Imagem do lugar de B para o sujeito colocado em A - Quem é ele para que eu lhe fale assim?

IB(B): Imagem do lugar de B para o sujeito colocado em B - Quem sou eu para que ele me fale assim?

$\mathrm{IB}(\mathrm{A})$ : Imagem do lugar de $A$ para o sujeito colocado em $B$ - Quem é ele para que me fale assim? (GADET \& HAK, 1993, p. 83, grifos nossos)

Existiriam regras de projeção responsáveis por estabelecer as relações entre as situações discursivas e as posições dos interlocutores. As relações imaginárias podem ser consideradas como um modo pelo qual a posição dos participantes do discurso intervém nas suas condições de produção.

Podemos concluir que, no processo discursivo, há, por parte dos interlocutores, uma antecipação das representações de um e de outro, sobre a qual se funda a estratégia do discurso. Como se trata de antecipações, o que é dito precede as eventuais respostas de B, que vão sancionar ou não as decisões antecipadas de A. Essas antecipações são, entretanto, sempre atravessadas pelo já dito, que constituem a substância das Formações Imaginárias.

Além disso, a AD nos permite, já que compactua com os princípios de Imaginário de Michel Maffesoli, compreender de que forma, nesses comentários, irrompem sentidos sobre a sexualidade e a homossexualidade feminina.

Quanto à análise de discurso de orientação francesa, destacamos que seus princípios, em termos gerais são:

a) O sujeito não é um ser humano com uma existência particular no mundo. Ao contrário, ele deve ser considerado como um ser social. E, em virtude disso, deve ser compreendido a partir de um espaço coletivo.

b) Sujeito e sentido se constituem ao mesmo tempo. Ao significar, o sujeito também se significa. Os lugares ocupados pelos sujeitos são, portanto, definidos a partir do que ele diz, a partir do que se materializa no seu discurso. Não é, portanto, uma teoria do sujeito determinado por uma enunciação pré-estabelecida: a partir de um sentido colado à palavra. Ao contrário, é uma teoria da instância de enunciação que é, ao mesmo tempo e intrinsecamente, um efeito de enunciado. 
c) Diante disso, é possível afirmar que as palavras não têm um sentindo literal. Para que elas façam sentido, é necessário que estejam inscritas na história, pois cada tempo tem a sua maneira de nomear e interpretar o mundo (ORLANDI, 1996). Esse é um complexo processo da memória. Há dizeres já ditos e esquecidos que estão em nós e que fazem com que, ao ouvirmos uma palavra, uma proposição, ela apareça como fazendo um determinado sentido. Para um analista de discurso, dessa orientação, o histórico e o simbólico não se separam. (ORLANDI, 2010).

d) A memória discursiva é constituída pelo esquecimento. Esquecemos quando os sentidos se constituíram em nós; eles nos aparecem como evidentes, como um sempre jálá.

e) Vivemos em uma sociedade estruturada pela divisão e por relações de poder, portanto, os sentidos não são os mesmos para todos, ainda que pareçam ser. Nós, analistas do discurso, tratamos do político que se inscreve na língua.

\section{A sexualidade na mídia: efeitos de sentido}

A escolha da mídia deve-se à expansão de sua circulação, nos dias de hoje, sobretudo, quando os textos midiáticos (referimo-nos também aos textos imagéticos) ganham mais espaços em sala de aula (em todos os níveis de escolarização), o que nos confere um grande poder na constituição do nosso sentimento de identidade e, ainda, porque, presentes em sala de aula, auxiliam na educação, na divulgação dos sentidos que são construídos por meio da veiculação de textos.

Sobre o aspecto pedagógico dos textos midiáticos, Beacco \& Moirand (1995) atribuem certo didatismo aos discursos das mídias, já que, para veicular informações, eles se valem de desenhos (mapas, figuras etc.), esquemas, além de definições, explicações, estatísticas, questionamentos e citações de autoridades (MARIANI, 1998, p. 61), enfocando, dessa forma, um acontecimento singular baseado em generalizações feitas a partir de um campo de saberes já estabelecido.

As mídias falam sobre, portanto, explicam o mundo como se se encontrassem fora dele, ou seja, como se a sua função fosse apenas a de relatar os fatos tais quais se apresentam lá fora - efeito de literalidade - e, assim, reforçam-se os mitos, construídos em torno 
desses discursos, de veracidade, de objetividade, de neutralidade e de imparcialidade. Sobre esses mitos, Mariani (2005) afirma que:

Trata-se de uma prática discursiva que atua na construção e reprodução de sentidos, prática essa realizada a partir de um efeito ilusório da função do jornal como responsável apenas por uma transmissão objetiva de informações. 0 discurso jornalístico constrói-se, dessa forma, com base em um pretenso domínio da referencialidade, pois baseia-se em uma concepção de linguagem que considera a língua como instrumento de comunicação de informações. Decorrem daí vários efeitos constitutivos dos sentidos veiculados como informações jornalísticas: objetividade, neutralidade, imparcialidade e veracidade. (MARIANI, 2005, p. 8, grifos nossos)

A linguagem, portanto, passa a ser concebida (e vendida) apenas como um instrumento de comunicação de significações, que são definidas independentemente do funcionamento da linguagem, isto é, “informações", mascarando a sua ligação com a prática política ou obscurecendo essa ligação. É importante, ainda, mencionar que as mídias são construídas com base em um pretenso domínio da referencialidade, como se falassem do mundo de um lugar distanciado, assim, o mundo é produzido como objeto a ser apresentado.

Ao introduzir o meio de comunicação, como jornais, revistas, fotografias, vídeos etc. para atividades pedagógicas, não se pode esquecer as próprias condições de produção das notícias e os efeitos de sentido decorrentes dessas mesmas condições. Nesse sentido, deve-se buscar - um dos nossos objetivos aqui neste capítulo compreender como objetos simbólicos, por definição não-transparentes, produzem sentidos, e os gestos de interpretação realizados pelos sujeitos. (ORLANDI, 2002, p. 27).

Compreende-se, a partir do que foi dito acima, que o discurso midiático tem por característica atuar na institucionalização de sentidos, o que significa dizer que ele contribui para a constituição do imaginário social e para a cristalização da memória do passado, bem como para a construção da memória do futuro.

Payer (2005), sobre o discurso da mídia, afirma que: 
Tudo indica que um novo Texto vem adquirindo o valor de Texto fundamental na sociedade contemporânea. Este grande texto da atualidade, no meu modo de entender, consiste da Mídia, daquilo que está na mídia, em um sentido amplo, e em especial no marketing, na publicidade. $O$ valor que a sociedade vem atribuindo à mídia - ou o poder de interpelação que a Mídia vem exercendo na sociedade - passa a assegurar-lhe o papel de Texto fundamental de um novo grande Sujeito, - Mercado, agora em sua nova forma globalizada. A mídia pode ser assim considerada como o Texto fundamental do Mercado na medida em que se compreende texto como a forma material do discurso, como propõe Orlandi (2001), como o lugar material em que a relação entre língua e ideologia produz seus efeitos, uma vez que, conforme a autora, "a ordem do discurso se materializa na estruturação do texto" (2001, p.89), e ele é "o lugar da relação com a representação física da linguagem, onde ela é som, letra, espaço, dimensão direcionada, tamanho - material bruto -, mas é sobretudo espaço significante" (idem). (PAYER, 2005, p. 15-16, grifos nossos)

Na constituição da memória social, da qual a mídia é parte e fundamental, o processo histórico-discursivo, resultante de uma disputa de interpretações dos acontecimentos presentes e passados (e futuros), leva à predominância de uma interpretação em detrimento a outras. Naturalizam-se, assim, sentidos que passam a ser comuns e hegemônicos. Isso não significa, porém, que os sentidos "esquecidos” deixem de atuar, seja como oposição, seja como resíduo no interior do discurso predominante. Essas interpretações aparecem como conteúdos que seriam colocados em circulação, em sentidos já estabilizados, divididos politicamente.

Duas perguntas básicas me motivam a pesquisar os textos midiáticos: a) Quais são as formas de linguagem e de sujeito que estão sendo requisitadas nas atuais condições de produção? b) Qual é o lugar, diante da proliferação cotidiana de linguagens na mídia, da memória pessoal, cultural e social?

Um dos conceitos fundamentais da $A D$ é o de condições de produção. As condições de produção caracterizam o discurso, o constituem na medida em que remetem a

lugares determinados na estrutura de uma formação social, lugares dos quais a sociologia pode descrever o feixe de traços objetivos característicos: assim, por exemplo, no interior da esfera da produção 
econômica, os lugares do "patrão" (diretor, chefe da empresa etc.), do funcionário de repartição, do contramestre, do operário, são marcados por propriedades diferenciais determináveis. (PÊCHEUX, 1995, p. 82, grifos nossos)

A memória das significações de um discurso e suas condições de produção não é secundária, mas constitutiva da própria significação. O lugar ocupado por cada sujeito, na estrutura de uma formação social: patrão, contramestre, operário, pode ser determinante para os sentidos. A língua é estrutura e acontecimento e só funciona por isso. Payer (2005) afirma que:

O que estamos querendo ao trazer à cena estes elementos de ordem aparentemente externa à linguagem, vamos dizer de ordem econômica, social e política no sentido amplo, é circunscrever agora um fato mais propriamente discursivo: é que a transformação no poder das instituições sociais se faz acompanhar de uma transferência de poder entre enunciados. Ou seja, em cada tempo histórico há enunciados que funcionam como fundamentais, enquanto máximas capazes de condensar o conteúdo que exerce a "interpelação ideológica dos indivíduos em sujeito", para retomar a conhecida expressão de Althusser. Consequentemente, com a alteração das instâncias do Poder, de um tempo histórico para outro, alteram-se também os enunciados fundamentais das práticas discursivas. (PAYER, 2005, p. 14-15, grifos meus)

A autora pressupõe o texto da mídia como aquele que assume, atualmente, o papel de fazer circular formas de identificação entre os sujeitos. Como os meios de comunicação de massa têm por característica a amplificação da informação, eles acabam por produzir informações de dimensões gigantescas em um espaço de tempo cada vez menor.

Com a expressão Aparentemente externa à língua, a autora refere-se ao imaginário de que a língua funciona independentemente das suas condições de produção: ou seja, um imaginário de que aquilo que é dito só poderia ser dito daquele jeito e de nenhum outro, como se os sentidos fossem colados às palavras e como se a língua fosse, de tal modo, transparente a ponto de significar exatamente 'O' sentido.

Silva (2002), quando apresenta, por exemplo, o processo de institucionalização da 
televisão brasileira, descreve-o com base num sistema comercial e propõe pensar a TV como espaço enunciativo, tanto de produção, como de circulação de sentidos. Em outro texto, a autora reafirma como a televisão, num determinado momento da história do Brasil, serviu como ‘um aparelho do Estado' para levar a cultura e a escrita à população.

O momento de expansão da televisão brasileira, na direção de sua institucionalização, é o momento em que se daria uma 'democratização da escola' [...] Mostram-se aí determinações políticas e econômicas no sentido de 'cultura' que 'integra' e marginaliza o sujeito pela identificação com o que é próprio ao urbano-moderno, como consumo, acesso, status, em um mesmo processo civilizatório. Assim, em termos das tecnologias da linguagem, ao invés de 'levar a escrita a todos', através da Escola, a 'informação e cultura' foi levada ao audiovisual, na forma de uma televisão brasileira. (SILVA, 2007, p. 94, grifos nossos)

A televisão é pensada pelo Estado como 'A' possibilidade de acesso à informação pelo público, por conta da sua materialidade. A TV é tomada como "o grande meio de comunicação", por ser considerada como a que tem maior acesso. Ou, ainda, como afirma Orlandi (2001, p. 179), a televisão tem a "capacidade de circulação em meio a uma grande massa heterogênea de sujeitos”. Os meios de comunicação funcionam, portanto, produzindo homogeneização e apagando as diferenças.

\section{Corpus e análise}

O nosso corpus foi organizado a partir dos comentários feitos por internautas anônimos no site do Youtube, em decorrência da postagem, no dia 19 de março de 2015, da cena exibida na novela Babilônia, da Rede Globo de televisão, às 21 horas, horário difundido pela própria emissora como sendo o seu Horário Nobre.

O vídeo não ultrapassa o tempo de 18 segundos de reprodução e constitui-se, como já sinalizamos acima, no resumo desse artigo, basicamente a partir de um beijo entre as personagens Teresa e Estela, interpretadas, respectivamente, pelas atrizes Fernanda Montenegro e Nathalia Timberg. Além do beijo, as personagens trocam carinhos e palavras que expressam afetos. 
Esses comentários foram acessados durante o processo de elaboração deste texto, maio de 2015, e selecionados usando como critério os discursos que expressam os imaginários sobre a sexualidade, os quais reproduzem padrões heteronormativos. Foram excluídas, dessa nossa seleção, todas as respostas produzidas a partir de comentários defendendo a postura das personagens, em termos de afirmação positiva da sexualidade homossexual. Foram postados catorze comentários e selecionados apenas sete para análise.

O próprio fato de a cena ter sido reproduzida à exaustão, nesse site, já significa muito: beijos entre personagens de sexos opostos passariam despercebidos pelo espectador e não mereceriam tal atenção. Por que beijos entre personagens do mesmo sexo não poderiam passar pela mesma indiferença? O que significam esses beijos na atualidade? Quais sentimentos produzem, ao serem reproduzidos à exaustão?

Beijos entre personagens de sexos opostos, mas da terceira idade, merecem também certa atenção, já que, em geral, não se diz muito sobre a sexualidade entre pessoas da terceira idade. No entanto, esse mesmo (outro) beijo, sendo produzido por duas senhoras, produz ainda mais sentidos, em virtude de tudo o que se sabe e se diz sobre a relação entre pessoas do mesmo sexo.

\section{1 - Análise dos comentários sobre a cena}

É importante, antes de iniciarmos as nossas análises, dizer que, por comentários, compreendemos o que Foucault (1970, p. 24-26) afirma sobre o seu funcionamento, ou seja, que eles permitem, a partir do texto, primeiro construir indefinidamente novos discursos, ritualizando, dessa forma, o que no primeiro texto havia sido dito, fundando uma possibilidade aberta de falar. Por outro lado, os comentários permitem dizer, enfim, o que estava articulado silenciosamente no texto primeiro, realizando-o.

$\mathrm{SD}(1)$. K nojo 2 senhoras e atrizes de respeito fazendo sem vergonhice na TV. Affs ${ }^{2}$.

\footnotetext{
${ }^{2}$ Optamos por não realizar qualquer alteração gráfica ou ortográfica nos comentários aqui analisados. Eles se encontram exatamente como aparecem quando da sua postagem.
} 
A SD(1) expressa como a troca de afeto entre pessoas do mesmo sexo e, sobretudo, entre senhoras, é considerada uma atitude desrespeitosa e imoral. De uma forma geral, no imaginário social, reproduzido aqui nessa postagem, a sexualidade ainda é fundamentada nos princípios da heteronormatividade, ou seja, há uma polaridade entre o que se considera normal e anormal. Tudo o que diz respeito aos comportamentos heterossexuais encontra-se num dos polos, o da normalidade, e tudo o que não diz encontra-se no outro polo.

Apesar desse beijo não ser o primeiro em horário nobre na mídia, há um elemento a mais que produz sentidos aos que defendem o que chamamos de normatização compulsória dos comportamentos: as atrizes que protagonizaram a cena são "senhoras" e, por isso, trazem à tona um novo problema sobre a sexualidade porque diz respeito à velhice. Foucault (1988), quando fala sobre o sujeito homossexual, afirma que ele se tornou apenas o seu sexo e que, por conta disso, não há nada que possa identificá-lo de outra forma. Todas as atenções se voltam, portanto, para as suas práticas sexuais.

O homossexual do século XIX torna-se uma personagem: um passado, uma história, uma infância, um caráter, uma forma de vida; também é morfologia, com uma anatomia indiscreta e, talvez, uma fisiologia misteriosa. Nada daquilo que ele é, no fim das contas, escapa à sua sexualidade. Ela está presente nele todo: subjacente a todas as suas condutas, já que ela é o princípio insidioso e infinitamente ativo das mesmas; inscrita sem pudor na sua face e no seu corpo já que é um segredo que se trai sempre. É-lhe consubstancial, não tanto como pecado habitual porém como natureza singular. É necessário não esquecer que a categoria psicológica, psiquiátrica e médica da homossexualidade constituiu-se no dia em que foi caracterizada - o famoso artigo de Westphal em 1870, sobre as "sensações sexuais contrárias" pode servir de data natalícia - menos como um tipo de relações sexuais do que como uma certa qualidade da sensibilidade sexual, uma certa maneira de interverter, em si mesmo, o masculino e o feminino. (FOUCAULT, 2005a, p. 43, grifos nossos)

Não há passado, não há presente ou futuro fora dessas amarras: nada escapa a sua sexualidade. Comete-se um crime, as manchetes dos jornais estampam “Homossexual matou..."; se estabelecer algum ganho, as manchetes também são organizadas a partir da sua sexualidade. 
Além disso, não se diz muito sobre as relações afetivas e muito menos sobre as sexuais, em relação à terceira idade. Nas novelas, de uma forma geral, quando se mostram casais heterossexuais na velhice, eles desempenham apenas os papéis convencionais, atribuídos aos mais velhos. São os avós preocupados com o seu dia a dia. Velhos não têm sexualidade na televisão aberta. Quando são velhos e homossexuais, não Ihes resta quase nada nas tramas das telenovelas.

No entanto, sabemos que, diferentemente do que paira nos imaginários, de uma forma hegemônica, no que se refere ao amor e à sexualidade, essa faixa etária é tão produtiva como qualquer outra. "Infelizmente, existem muitos mitos que dificultam a compreensão de como a vivência do amor e da sexualidade está relacionada com pessoas de idade avançada" (ALMEIDA, LOURENÇO, 2008, p. 131).

A sociedade, na maioria das vezes, compreende a velhice como um período assexual, decorrente de concepções restritas de sexualidade. Nessa fase da vida, caberia ao sujeito a função de avô ou de avó e, concomitantemente, realizar atividades como fazer tricô e assistir à televisão, usufruindo de sua aposentadoria (RISMAN, 2005). Ou, no máximo, quando se trata de telenovelas, a procura de um parceiro da mesma faixa etária, sem qualquer ousadia sexual ou afetiva.

Se a sexualidade na velhice já produz incômodo, se a sexualidade da mulher também produz incômodo, se a sexualidade homossexual-feminina produz ainda mais incômodo, imaginemos a visibilidade da homossexualidade-feminina-na-terceira-idade. Essa cena causou impacto por trazer de uma só vez todos esses elementos comumente silenciados.

Interessa-nos, aqui, também discutir como são ocupados os lugares que podem/devem falar sobre a sexualidade nos meios de comunicação. Quem sou eu para Ihe falar assim? Como eu me vejo? Como vejo a minha sexualidade? Como vejo a sua sexualidade? Como imagino ser visto para que eu lhe fale assim?

$\mathrm{SD}(2)$. Agora me sinto à vontade para peidar em qualquer lugar. 
Os padrões de comportamento sociais são fortemente marcados na formação imaginária dos sujeitos e são expressos nessa analogia entre o beijo homossexual de velhas senhoras com o flato, que, em nossa sociedade ocidental, é encarado como ausência de polidez, falta de educação, grosseria.

Os flatos, causados pelos "restos alimentares, por ação de bactérias intestinais, sofrem uma degradação, principalmente, no intestino grosso, o que resulta na produção de, aproximadamente, três litros de gases por dia"3, são uma necessidade do organismo.

A analogia inscreve o beijo entre pessoas do mesmo sexo às práticas consideradas, no mínimo, desrespeitosas. Ainda que seja uma necessidade do organismo, como afirmamos acima, há um controle social em relação ao flato: ele é da ordem do privado. Publicamente, você não deve sequer mencioná-lo. Até falar sobre ele produz incômodo. Nessa perspectiva, o beijo entre pessoas do mesmo sexo também produz um incômodo. A gente sabe que existe, mas é melhor não falar sobre ele.

No entanto, há aqui, digamos, um equívoco, quando da associação entre o flato e o beijo entre as senhoras, tendo em vista que aquele, ainda que não se "deva" realizar publicamente por estar associado às práticas de falta de educação, é natural. Não se pode negar que os flatos são respostas do organismo em virtude de algo que ele precisa expelir. Assim, ao se comparar flatos e beijos entre pessoas do mesmo sexo, poderíamos concluir que, mesmo causando incômodo, eles são naturais. E mais, são necessidades que não podem/devem ser silenciadas.

SD(3). Nossa!!!! É chocante e lamentável essa cena pois é o que sempre falo estão a todo custo tentando enfiar de garganta abaixo esse comportamento, querem obrigar a sociedade a aceitar isso mas surge a pergunta: será que conseguem? ... felizmente pelo que vejo por aí ainda tem muita gente que tem uma grande resistência a esse ato... e a Globo quer a todo custo com cenas como essa normalizar aquilo que não é normal mas não adianta afinal o povo não é trouxa e não vai se deixar influenciar com tudo isso pois pra evitar basta mudar de canal pra ver alguma coisa que preste.

\footnotetext{
${ }^{3}$ http://www.abcdasaude.com.br/medicina-interna/gases.
} 
Segundo a SD(3), o que fica evidente são os sentidos sobre uma certa imposição da mídia em relação ao comportamento não-heterossexual. O comentário nos mostra, por meio de palavras e expressões, tais como, "enfiar garganta abaixo esse comportamento", "a todo custo", "aceitar isso”, “esse ato”, "normalizar aquilo que não é normal” e "o povo não é trouxa" como os meios de comunicação tentam naturalizar aquilo que não é/que não pode ser normal.

Por outro lado, nada que se diz sobre a heterossexualidade é posto em xeque. Não se questiona o que é normal. Em nosso imaginário, tratamos a heterossexualidade como axioma e essa suposição impede que ela seja examinada, o que provoca um silêncio, constantemente repetido na prática. A heterossexualidade é tratada como se sempre-lá, como se tivesse estado presente em todas as categorias mentais - por isso, nunca é questionada. (KATZ, 1996).

Diante disso, colocamos em pauta as seguintes considerações: e a corrupção nas empresas e entre os políticos, os casos de infidelidade heterossexuais, os relacionamentos entre homens mais velhos e meninas menores de idade, as falcatruas para levar vantagem, o desvio de caráter, os assassinatos em família ou entre desconhecidos, o aliciamento da filha, os preconceitos de diferentes origens, a exposição dos corpos femininos, o abandono de filhos, os maus-tratos com idosos?

Poderíamos escrever muitas páginas com exemplos de padrões de comportamentos explicitados nas cenas das novelas as quais assistimos cotidianamente e que, no entanto, não provocam indignação: Por que será que esses desvios não nos afetam? Não nos causam estranhamentos? Não denigrem a família brasileira? Não corrompem as crianças e os adolescentes? Não movem da mesma forma as pessoas que insistem em não aceitar a homossexualidade como uma das formas de viver a sexualidade? Supomos que o nosso moralismo condena um dos aspectos da constituição humana, a sexualidade? E condena de forma mais incisiva a homossexualidade.

Nos anos 1990, do século passado, a homossexualidade foi retirada do Código Internacional de Doenças - CID, e passou a ser considerada como uma das expressões da sexualidade, no entanto, algumas pessoas insistem em continuar sua patologização, afirmando que não é normal. O limite entre normal e anormal, entre patológico e saudável é tênue e, no caso da sexualidade, foi construído com o auxílio das ciências - 
medicina, psicologia, e das instituições - igreja, família, escola e mídia. As religiões, compreendidas aqui como a crença em algo metafísico, têm muita responsabilidade na acepção da homossexualidade como doença, uma vez que os casais homossexuais não poderiam procriar e praticariam atos sexuais abominados pela lgreja, como por exemplo, o sexo anal. A prática sexual de pessoas do mesmo sexo existe desde os primórdios da humanidade, no entanto, é no século XIX que as pessoas são classificadas conforme suas práticas sexuais. Há diferentes dispositivos que tentam controlar a sexualidade e o discurso entre normal e anormal; saudável e patológico é um deles.

SD(4). Afronta? então agora a liberdade expressão virou afronta ?... sim é verdade que cada um tem livre arbítrio pra ser e fazer o que desejar mas não podemos esquecer que a nossa Constituição nos dá direitos de si posicionar em relação a qualquer assunto inclusive a respeito ao homossexualismo, digo isso pois a maioria deles não suportam a opinião contrária sendo assim é bem mais fácil transformar opinião em preconceito pra ver se assim colocam amordaça em cada um que tiver opinião diferente mas comigo e com muitos outros esse jogo sujo não funciona.

A constituição sempre é um argumento colocado na ordem do dia para se pensar na liberdade de expressão. E assim deve ser. Por outro lado, o mesmo documento quase nunca é citado quando se falam dos direitos de todos perante a lei. O Art. $5^{\circ}$ da Constituição nos diz que:

Todos são iguais perante a lei, sem distinção de qualquer natureza, garantindo-se aos brasileiros e aos estrangeiros residentes no País a inviolabilidade do direito à vida, à liberdade, à igualdade, à segurança e à propriedade. (Constituição de 1988, grifos nossos)

Sem distinção de qualquer natureza coloca tanto o hétero quanto o homossexual num mesmo lugar. Não se pode, portanto, em nome da Lei, que regula os direitos e deveres, no âmbito de cada Estado da Federação, elaborada e aprovada pela Assembleia Legislativa, pensar que ela legisla sobre a liberdade de expressão, mas que não legislaria sobre o fato de não fazer distinção de qualquer natureza em relação aos cidadãos. 
Viver numa sociedade democrática não é destilar nossos preconceitos contra as minorias, nos favorecendo da bandeira da liberdade de expressão. Comumente, temos confundido liberdade de expressão com discurso de ódio. Infelizmente, muitas vezes, a liberdade de expressão fundamenta-se em opiniões que desconsideram as ciências, os dados estatísticos e as pesquisas.

Não aceitar a homossexualidade como uma forma de viver a sexualidade é um direito das pessoas; assim como também é direito de outras pessoas manifestarem os seus desejos e afetos com pessoas do mesmo sexo.

Ainda sobre essa SD, o emprego do termo "homossexualismo" não é simplesmente uma questão de semântica, mas, de conceitos. A partir dos anos 1980, as instituições de saúde começaram a rever os significados dessa forma de vivenciar a sexualidade; em 1985, o Conselho Federal de Medicina, no Brasil, desconsiderou o parágrafo 302.0 do Código Internacional de Doenças - CID, da Organização Mundial da Saúde - OMS, que classificava o "homossexualismo" como desvio e transtorno sexual. Em 1991, a Anistia Internacional começou a considerar violação dos direitos humanos a proibição da prática homossexual. Em 1993, a OMS tornou sem efeito o código 302.0. (FURLANI, 2007, p. 154).

O sufixo "ismo" remete à doença, assim, nos anos 1990, quando essa forma de viver a sexualidade foi retirada do Código Internacional de Doenças - CID e, por influências acadêmicas e das lutas da população Lésbicas, Gays, Bissexuais, Transexuais e Travestis - LGBTT, o termo em voga foi ressignificado por homossexualidade. A homossexualidade é uma forma de viver a sexualidade, tal como a heterossexualidade e a bissexualidade e tantas outras que possam ser descobertas.

SD(5). Querido veja a incoerência de sua colocação "...ninguém deve expor sua opinião sobre a homossexualidade..." então quer dizer só gays podem colocar sua opinião sobre sua prática (pq eles fazem isso em várias partes da mídia e fora dela) e o outro lado não pode, é isso? isso é igualdade ?... lógico que não... a verdade que eles tem medo de ouvir uma opinião que não é a sua, a respeito da "pele negra" ou "heterossexualidade" não pode comparar essas coisas com homossexualismo pois a diferença entre eles é bem notória... como diz nossa Constituição "...ninguém será privado de direitos por convicção religiosa, filosófica ou política..." sendo assim podemos sim colocar nossa 
opinião sobre qualquer assunto existente, porém não podemos tentar impor nossa opinião a ninguém, o que podemos é apresentar nossa visão sobre o assunto e a pessoa que lê ou escuta é que vai decidir se aceita ou não, sendo assim eu respeito mas aceitar "NUNCA".

A questão em relação à $\operatorname{SD}(5)$ é a de que a homossexualidade pode/deve ser questionada enquanto a heterossexualidade não. Como já nos referimos acima, tratamos a heterossexualidade como onipresente. A homossexualidade, por sua vez, ocupou a posição antagônica nessa normalidade, por isso, pode ser questionada em qualquer tempo.

Segundo KATZ (1996), as categorias sexuais, que hoje nos parecem familiares, não eram conhecidas, por exemplo, na antiguidade grega, de maneira que as suas origens são recentes e sua história cheia de conceitos variáveis e contestada:

As categorias sexuais que são tão óbvias para nós, as que dividem a humanidade em heterossexuais e homossexuais, não parecem ter sido conhecidas pelos antigos gregos. Esse autor nos preveniu de que precisamos evitar projetar as nossas categorias atuais sobre as sociedades passadas, que organizavam as pessoas e a sexualidade seguindo linhas muito diferentes. (KATZ, 1996, p. 22, grifos nossos)

Ainda, segundo esse autor, o discurso histórico sobre a heterossexualidade é uma invenção moderna. O termo heterossexualidade, que pretendia descrever um sexo-amor mais velho que Matusalém, é de origem bastante recente e tem uma história de definições variáveis e contestadas. (KATZ, 1996).

Na SD acima, a heterossexualidade pode ser comparada com a cor da pele, porque é natural. Ser heterossexual é como ser branco ou preto: nasce assim e pronto. A homossexualidade, por outro lado, é uma escolha. Outra vez temos aqui um embate entre o normal versus o anormal; o natural versus antinatural.

$\mathrm{SD}(6)$. Querido existe uma diferença monumental entre ser hétero e negro em relação a ser gay pois ser hétero é ser fiel ao gênero humano (a saber masculino e feminino ) o que passa disso vira confusão, na outra parte querer comparar homossexualismo com "cor da pele" é muita 
apelação pq não se escolhe a cor da pele desejada, a pessoa nasce e pronto já o homossexualismo é comportamental o que não é o mesmo em relação a raça... olha, não estou dizendo que as pessoas devam deixar essa prática pois se a mesma afirma ser feliz assim (algo que sinceramente duvido muito) que seja ! que viva assim então ! agora o que não pode é querer obrigar as demais pessoas acharem isso bonitinho afinal isso não é normal nem hoje, nem amanhã e nem nunca será, digo e repito podemos até conviver com esse "ato" mas aceitá-lo "NUNCA".

Esse comentário tece uma breve analogia entre a raça e a orientação sexual, ao justificar que a primeira não é escolha, já a segunda é comportamental. Ou seja, as pessoas escolhem se serão ou não homossexuais. No entanto, ser heterossexual não é uma escolha porque é natural.

Muitas pesquisas e teorias buscam as gêneses (biológicas, psicológicas, sociais, até espirituais) da homossexualidade, como se os homossexuais tivessem algo a mais ou a menos do que os outros sujeitos; ou que sofreram algum desvio no desenvolvimento sexual “normal” (FILHO, 2009). Nesse sentido, consideramos pertinente ressaltar que:

Definida em termos de orientação ou expressão sexual, a homossexualidade não é uma opção que depende da vontade do indivíduo, como uma deliberação consciente, mas nenhuma orientação sexual o é, assim como não é algo da ordem de uma causa específica. Se há que se falar de causa, a causa da homossexualidade é a mesma de toda orientação/expressão sexual, a mesma da sexualidade humana como tal: a pulsão sexual sobre a qual se estrutura o desejo que, como Freud a caracterizou, não tem objeto nem fixo nem único, não determina nenhum objetivo como natural ou normal, e faz suas escolhas segundo uma economia cujo único princípio é o prazer (Freud, 1905 [1972], entre outros textos do autor). Assim, heterossexualidade, homossexualidade ou bissexualidade são nomenclaturas usuais (todas com sentidos culturais e históricos) para expressões sociais do desejo sexual humano calcadas na pulsão. A sexualidade ligada à pulsão e ao desejo não se estrutura por uma disposição orgânica ou em dados fisiológicos. (FILHO, 2009, p. 114, grifos do autor)

Além da suposição que a homossexualidade seja aprendida, a SD(6) explicita a concepção de que há uma forma natural e normal de identidade de gênero, que é a cisgênero, a qual é determinada pela questão biológica, chamada sexo. Nasce-se homem, 
logo, masculino. Nasce-se mulher, logo, feminina, negando qualquer outra possibilidade de identidade de gênero.

Parece-nos que a não aceitação de outras formas de sexualidade e de identidade de gênero apela, na maioria das vezes, para o conceito de normal ou natural, como já nos referimos acima, como se a sexualidade e o gênero fossem definidos no nascimento do sujeito e permanecessem rígidas. Essa concepção descontrói esses constituintes da vida como históricos, sociais, culturais, dentre outros. Pensar, a partir dessa rigidez, nos leva a considerar que existe somente uma maneira de viver a sexualidade e o gênero, ao passo que as práticas e os discursos têm nos comprovado o contrário.

“Não estou dizendo que as pessoas devam deixar essa prática pois se a mesma afirma ser feliz assim (algo que sinceramente duvido muito) que seja”. Esse excerto do comentário, de cunho judicativo, traz à tona uma discussão filosófica sobre felicidade. A felicidade foi e é tema dos filósofos; a referência mais antiga é um fragmento de um texto de Tales de Mileto, que viveu entre as últimas décadas do século 7 a.C. e a primeira metade do século 6 a.C. Para ele, é feliz "quem tem corpo são e forte, boa sorte e alma bem formada". Vale ressaltar a expressão "boa sorte", pois dessa dependia a felicidade na visão dos gregos mais antigos.

A felicidade, tema de diferentes pensadores (Sócrates, Epicuro, Platão, Aristóteles e outros.) e de grandes controvérsias, tem seus sentidos ressignificados pelas pessoas que a vivem.

Nesse sentido, chama-nos a atenção quando um sujeito coloca em dúvida a felicidade do outro, por ele não seguir os seus padrões de comportamento. Desse modo, a SD acima naturaliza que a felicidade somente é alcançada quando seguirmos os padrões normais e naturais, e desnaturaliza que os padrões são construídos na e pela sociedade, por isso, são passíveis de mudanças, de ressignificações. O natural e o normal variam de pessoa para pessoa, inclusive, o próprio conceito de felicidade é escorregadio e frívolo.

$\mathrm{SD}(7)$. pronto....já teve de jovens, agora de senhoras, daqui a pouco a globo vai colocar duas crianças pra dizer lá na frente eles se amavam desde a infância......Acho a rede globo imoral. 
O apelo é sempre o mesmo, ou tem por base o mesmo. Em todas as SDs analisadas, a questão moral e a relação entre o natural/normal versus o antinatural/anormal são postos como princípios que não podem/devem ser abalados.

Aqui, na SD(7), o apelo se faz em relação à sexualidade das crianças. É como dizer: Só falta a Rede Globo explorar a sexualidade infantil. O efeito de sentido que se quer efetivar é o de que é tão absurdo o que se faz ao colocar duas senhoras se beijando, quanto seria o de sexualizar duas crianças.

Além disso, tem ainda aqueles sentidos que também se cristalizam de que pais homossexuais influenciam o comportamento de filhos em potencial. De que crianças aprendem a homossexualidade ao assistirem as cenas veiculadas nas novelas. De que a criança é pura e, por isso, não pode/deve ser exposta a nada que diz respeito à sexualidade, sobretudo, à homossexualidade.

\section{Considerações finais}

Há, como é possível analisar nos imaginários sociais expressos nos comentários publicados em relação ao vídeo que retrata a cena do beijo da novela Babilônia, exibida pela Rede Globo de Televisão, em horário nobre, os sentidos recorrentemente reproduzidos, quando os afetos entre pessoas do mesmo sexo são exibidos nos meios de comunicação: incômodo, repulsa, doença, nojo, pecado, sem-vergonhice, entre outros.

Fica evidente na trama a insignificância pela qual o casal homossexual passou a ser abordado. As personagens estão relegadas ao segundo plano, na novela escrita por Gilberto Braga, Ricardo Linhares e João Ximenes Braga. Não há qualquer resquício do que se anunciava em relação à participação das senhoras atrizes e de seus personagens. $O$ casamento entre elas não passa de discussões sobre a relação entre as duas, muito diferentemente de qualquer outra relação heterossexual, retratada na mesma novela.

E não seria necessário sequer haver beijo entre os personagens para que as manifestações fossem ao nível da intolerância. Recentemente, O Boticário, empresa de produtos de perfumaria, cosméticos etc., ao veicular um comercial, em comemoração ao Dia dos namorados, no qual apresenta três casais: um casal heterossexual e dois casais homossexuais, houve, por parte de algumas representações evangélicas, manifestações 
de repúdio à propaganda e proposta de boicote à empresa. Nessa peça publicitária, os casais apenas se abraçam e entregam presentes comprados nO Boticário.

O imaginário, claro que em se tratando de uma forma generalizada, é o de que eu, o normal, posso me sentir ofendido, nesse caso específico, por qualquer manifestação de afeto entre pessoas do mesmo sexo. Além disso, os sentidos de que a homossexualidade põe em risco a "Tradicional Família Brasileira" e a sociedade são recorrentes nos comentários em relação à cena exibida. Esses comentários articulam-se no imaginário social, pois, "pode-se falar em meu ou teu imaginário, mas, quando se examina a situação de quem fala assim, vê-se que o seu imaginário corresponde ao imaginário de um grupo no qual está inserido" ( MAFESSOLI, 2001b, p. 76). Esses comentários podem expressar imaginários de outras pessoas que comungam do mesmo grupo social.

Somam-se a isso, os fatos de que se trata da sexualidade feminina, da homossexualidade feminina e, sobretudo, da sexualidade homossexual feminina na velhice.

Se pensarmos no conceito de Fl, Gadet \& Hak (1993), poderíamos mencionar que A, o sujeito que produz os comentários, em relação a $B$, ao casal de mulheres velhas, se coloca em uma posição de poder/dever julgar outras formas de sexualidade, como sendo anormal, já que a sexualidade de $\mathrm{A}$ não se pode questionar, visto que se trata da heterossexualidade.

Heterossexualidade aqui compõe uma equação linguística com os termos normal, família, natural, saudável etc.

Chamo de equação linguística, locução cunhada por Mariani (1998: 18)", para designar a equivalência de sentidos (no caso da homossexualidade, negativos) entre duas ou mais expressões produzidas e recorrentes no interior de uma determinada formação discursiva a partir de certas condições de produção de sentido. (SOARES, 2006, p. 64, grifos nossos)

\footnotetext{
4 "O comunista é um inimigo". Nesta "equação linguística" - "comunista = inimigo" -, a qual fixa um "lugar do mal” na história do Partido no Brasil, na forma como foi apresentada pela imprensa não-partidária, se encontra um sentido sempre-já negativo, reiterado na forma de diferentes denominações ou como elemento integrante de narrativas políticas. (MARIANI, 1998, p. 18, grifos nossos).
} 
E homossexualidade, por sua vez, só pode/deve compor sentidos, nessas condições de produção, com os termos: anormal, antinatural, pecado, erro, doente etc.

A autoimagem de A lhe permite falar sobre B desse jeito porque esses sentidos também significam os sujeitos homossexuais, no Brasil contemporâneo.

No entanto, outros sentidos em nossos imaginários também são produzidos a partir da cena e comentários analisados, significando que há um embate produzido sobre a homossexualidade: se, de um lado há os sentidos de doença, anormalidade etc., há, por outro, os sentidos de afeto, de amor, da sexualidade na velhice entre pessoas do mesmo sexo como recorrente, como parte do social em busca de visibilidade.

Os comentários trazem à tona sentidos que não estavam presentes no texto original (a cena do beijo entre as personagens), mas que se colam socialmente ao homossexual e a sua sexualidade, ainda no século XXI. Aqueles velhos sentidos de anormalidade, antinatural ou mesmo doença, de séculos anteriores, presentes nos imaginários e expressos nos discursos, por exemplo, são sempre ressignificados quando se trata desse sujeito.

A sexualidade, suas vivências e suas expressões, ainda, movem contrariedades. Se de um lado temos novelas com beijos de pessoas do mesmo sexo ou campanhas publicitárias com alusão à homossexualidade, por outro, prevalece, em grande parte do imaginário social, a cristalização dos padrões heteronormativos e posições judicativas, a respeito da sexualidade que não se enquadra a esses padrões. Quiçá, seja o movimento entre o tradicional e o moderno, entre o proibido e o permitido e tantos outros, que envolvem a sexualidade, que a tornem uma temática tão sedutora. 


\section{Referências}

Almeida, Thiago de. Lourenço, Maria Luiza. Amor e sexualidade na velhice: direito nem sempre respeitado. RBCEH, Passo Fundo, v. 5, n. 1, p. 130-140, jan./jun. 2008.

BEACCO, Jean-Claude; MOIRAND, Sophie. Autour des discours de transmission des connaissances. Langages, n. 117, Paris: Larousse, 1995.

BRASIL. Constituição da República Federativa do Brasil. Brasília, DF: Senado Federal, Centro Gráfico, 1988.

FILHO, Alípio de Sousa. Teorias sobre a gênese da homossexualidade: ideologia, preconceito e fraude. In: JUNQUEIRA, Rogério Diniz (Org.). Diversidade sexual na educação: problematizações sobre a homofobia nas Brasília: Ministério da Educação, Secretaria de Educação Continuada, Alfabetização e Diversidade, UNESCO, 2009.

FOUCAULT, Michel. A ordem do discurso. São Paulo: Edições Loyola,1970.

FOUCAULT, Michel. Microfísica do poder. Organização e tradução de Roberto Machado. $11^{\mathrm{a}}$ reimpressão. Rio de Janeiro: Edições Graal, 1995.

FOUCAULT, Michel. História da sexualidade II: o uso dos prazeres. Tradução de Maria Thereza da Costa Albuquerque e revisão técnica de J. A. Guilhon Albuquerque. $10^{\mathrm{a}}$ ed. Rio de Janeiro: Edições Graal, 2003.

FOUCAULT, Michel. História da sexualidade I: a vontade de saber. Tradução de Maria Thereza da Costa Albuquerque e J. A. Guilhon Albuquerque. $16^{\mathrm{a}}$ ed. Rio de Janeiro: Edições Graal, 2005a.

FOUCAULT, Michel. Arqueologia do saber. $7^{\mathrm{a}}$ ed. Rio de Janeiro, Forense-Universitária, 2005b.

FURLANI, Jimena. Mitos e tabus da sexualidade humana: subsídios ao trabalho em educação sexual. 3 ed. Belo Horizonte: Autêntica, 2007.

GADET, Françoise; HAK Tony (Org.). Por uma análise automática do discurso: uma introdução à obra de Michel Pêcheux. Campinas: Editora da Unicamp, 1993.

GUIMARÃES, Áurea Maria. O imaginário da violência e a escola. In: TEIXEIRA, Maria Cecília Sanchez; PORTO, Maria do Rosário Silveira (Orgs.). O imaginário do medo e cultura da violência na escola. Niterói: Intertexto, 2004, p. 59-71.

GUIMARÃES, Isaura. Educação sexual na escola: mito e realidade. Campinas: Mercado de Letras, 1995.

JESUS, Railda Maria Bispo de. Implicações da ação docente sobre as questões de sexualidade e gênero na escola. Revista Faced. Salvador, Universidade Federal da Bahia, 
n. 11, p. 189-199, jan./jun., 2007.

KATZ, Jonathan Ned. A invenção da heterossexualidade. Rio de Janeiro: Ediouro, 1996.

LOYOLA, Maria Andréa. A sexualidade como objeto das ciências humanas. In: HEILBORN, Maria Luiza (Org.). Sexualidade: o olhar das ciências sociais. Rio de Janeiro: Jorge Zahar Editor, 1999, p. 31-39.

LOURO, Guacira Lopes. Pedagogias da sexualidade. In: LOURO, Guacira Lopes (Org.). 0 corpo educado: pedagogias da sexualidade. Tradução de Tomaz Tadeu da Silva. $2^{\mathrm{a}}$ ed. $3^{\mathrm{a}}$ reimpressão. Belo Horizonte: Autêntica, 2007, p. 7-34.

MAFFESOLI, Michel. Sobre o nomadismo: vagabundagens pós-modernas. Tradução de Marcos de Castro. Rio de Janeiro: Record, 2001a

MAFFESOLI, Michel. O imaginário é uma realidade. Revista FAMECOS mídia cultura e tecnologia. Porto Alegre: Programa de Pós-Graduação em Comunicação Social da Faculdade de Comunicação Social da Pontifícia Universidade Católica do Rio Grande do Sul, n. 15, p. 74-82, ago. 2001b.

MAFFESOLI, Michel. A conquista do presente. Tradução de Alípio de Souza Filho. Natal: Argos, 2001C.

MAFFESOLI, Michel. A sombra de Dioniso: contribuição a uma sociologia da orgia. Tradução de Rogério de Almeida. $2^{a}$ ed. São Paulo: Zouk, 2005 .

MAFFESOLI, Michel. O mistério da conjunção: ensaio sobre comunicação, corpo e socialidade. Tradução de Juremir Machado da Silva. Porto Alegre: Sulina, 2005b.

MARIANI, Bethania Sampaio Corrêa. O PCB e a imprensa: os comunistas no imaginário dos jornais 1922-1989. Rio de Janeiro: Revan; Campinas: Editora da Unicamp, 1998.

MAFFESOLI, Michel. Para que(m) serve a psicanálise na imprensa?. 2005. Disponível em: <http://www.geocities.com/gt_ad/bethania.doc>. Acesso em 22 de julho de 2014.

ORLANDI, Eni. A linguagem e seu funcionamento: as formas do discurso. 4. ed. Campinas: Pontes, 1996.

ORLANDI, Eni. Discurso e texto: formulação e circulação dos sentidos. São Paulo, Pontes, 2001.

ORLANDI, Eni. As formas do silêncio. Campinas, Editora da Unicamp, 2002.

ORLANDI, Eni. (Org.). Discurso e políticas públicas urbanas: a fabricação do consenso. Campinas: Editoras RG, 2010.

PAYER, M. O. Sujeito e sociedade contemporânea. Sujeito, mídia, mercado. Rua, Campinas: Núcleo de Desenvolvimento da Criatividade da Unicamp, n. 11, março de 2005. 
PÊCHEUX, Michel. Semântica e discurso: uma crítica à afirmação do óbvio. Campinas: Editora da Unicamp, 1995.

RISMAN, A. Sexualidade e terceira idade: uma visão histórico-cultural. Textos sobre Envelhecimento, Rio de Janeiro, v. 8, n. 1, 2005.

SILVA, Telma D. A televisão brasileira: a comunicação institucionalizada. 2002, oof. Tese (doutorado em Estudos da Lingagem) - Universidade Estadual de Campinas, Instituto de Estudos da Linguagem. Campinas, SP, 2002.

SILVA, Telma D. Língua e linguagens: reflexões sobre a política cultural e a televisão no Brasil. Línguas e instrumentos linguísticos. Campinas: Universidade Estadual de Campinas: Pontes Editores, n.18, 2007.

SOARES, Alexandre S. Ferrari. A homossexualidade e a AIDS no imaginário de revistas semanais (1985-1990). 2006, oof. Tese (doutorado em Estudos da Linguagem) Universidade Federal Fluminense, 2006.

TEVES, Nilda. O imaginário na configuração da realidade social. In: TEVES, Nilda (Org.). Imaginário social e educação. Rio de Janeiro: Gryphus: Faculdade de Educação da Universidade Federal do Rio de Janeiro, 1992, p. 3-33.

WEEKS, Jeffrey. O corpo e a sexualidade. In: LOURO, Guacira Lopes (Org.). O corpo educado: pedagogias da sexualidade. Tradução dos artigos: Tomaz Tadeu da Silva. $2^{\mathrm{a}}$ ed.,

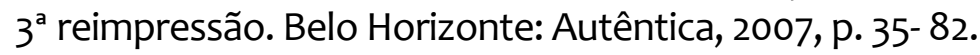

\section{Sites pesquisados}

<http://www.abcdasaude.com.br/medicina-interna/gases>.

<http://www.youtube.com>. 